\title{
Study on Innovation Cultivation Model and Practice for Engineering Talents in Transnational Higher Education
}

\author{
Yu Liu*, Boshuai Ye, Jing Liu, Chao Dong
}

Nanjing Institute of Technology

*Corresponding author.Email: liuyu0357@gmail.com

\begin{abstract}
Higher education institutions are the driving force of the country's development because of the innovations bred in higher education. Creativity is the key to innovation and the essential feature of innovative talents. At present, China's higher engineering education reform is standing at an important historical turning point, and the cultivation of engineering talents' innovative consciousness has become particularly important. This article selects the School of International Education of Nanjing Institute of Technology to study the training model of engineering students' innovative ability. Through research, it is found that the college has built a student-centered school-enterprise collaboration four-dimensional innovative talent training model through continuous exploration and practice. The innovation capability training model is based on the cultivation of student innovation capability, Finnish professional teachers and Chinese local enterprise tutors work together, professional courses and workshops are the basis, college students' engineering innovation training projects are the carrier, and various innovation competitions at all levels as the thrust , It is worth being promoted and used for reference.
\end{abstract}

Keywords: Talent Cultivation, Engineering Talents, Transnational Education.

\section{INTRODUCTION}

Higher education institutions are the driving force of the country's development, and the main reason is that higher education has nurtured innovation. Creativity is the key to innovation and the essential feature of innovative talents. At an important historical turning point in the reform of China's higher engineering education, the importance of the reform to the cultivation of innovative consciousness of engineering talents is selfevident. In 2016, China proposed the concept of new engineering education. In 2017, the Ministry of Education of China initiated the construction of "New Engineering". Compared with the past, The new fields of engineering education include artificial intelligence, big data, cloud computing, Internet of Things, block chain, etc. This means that the concept of traditional engineering education is being upgraded (Wu et al., 2017) [1]. Engineering education continues to expand in scale and quality. In addition to accelerating the development of new engineering majors, it also continuously upgrades and transforms traditional engineering majors, and pays attention to infiltrating humanistic literacy and professional ethics into engineering majors. Based on the concept of integration, coordination, and sharing, today's Chinese higher education is striving to cultivate strategic, innovative, systematic and open interdisciplinary innovative compound talents, so that they can cope with the rapidly changing external environment in the future (Zhong, 2017) [2]. In June 2017, all official members of the "Washington Accord" organization approved unanimously through China as the 18th official member of the "Washington Accord", which means that Chinese engineering education has achieved international multilateral mutual recognition, and Chinese higher education will truly go global.

Chinese President Xi Jinping (2018) pointed out at the 2018 National Education Work Conference that it is necessary to accelerate the opening up of education and carry out high-level cooperation with world-class universities [3]. This has brought new opportunities to the development of higher education, and has also put forward more stringent new requirements for higher education. One form of transnational higher education in 
China is the cooperation between foreign universities and Chinese universities to open educational projects or institutions in China to form a transnational Educational projects and institutions. As part of the opening up of China's education, it has its own unique advantages. Chinese students can obtain knowledge from foreign universities even if they do not go abroad. With the advent of globalization, transnational higher education plays an increasingly important role in my country's higher engineering education. At present, most overseas universities dedicated to the international development of higher education have also come to China to carry out different forms of higher education cooperation in running schools. And many multinational universities have made great achievements in the cultivation of innovative talents through practice.

This article aims to put forward several key elements in the cultivation of innovation capability of engineering students, and to solve the problems existing in the cultivation of innovation capability of undergraduates in engineering education in colleges and universities. Using the method of case study, it studied the innovation capability training of the software engineering students, which in the School of International Education (SIE) of Nanjing Institute of Technology, and proposed a studentcentred school-enterprise collaboration four-dimensional innovation talent training model and specific training paths. The first part is the introduction. The second part introduces and analyses the related literature on the cultivation of engineering innovative talents. The third part proposes a student-centred school-enterprise collaboration four-dimensional innovative talent training model based on the experience of cultivating engineering innovative talents in the School of International Education of Nanjing Institute of Technology and conducts in-depth discussions; the fourth part summarizes the commonality of innovative talent training Features.

\section{LITERATURE REVIEW}

Higher education institutions are the driving force of the country's development, and the reason is that higher education has nurtured innovation. University education is an important source of innovation, creating new and improved products and services, and providing training, professional knowledge and human resources, that is, potential innovators of society and organizations (AlHusseini, Ibrahim, 2014) [4]. Creativity is the key to innovation and the essential feature of innovative talents. Therefore, how to cultivate the creativity of college students so that they can grow to discover new phenomena and laws through the use of the knowledge they have mastered and the observation, analysis, synthesis, and evaluation of objective things, to propose new theories and methods, and to create new ones
Material products and ideological and cultural achievements are particularly important.

In recent years, the cultivation of engineering talents in higher education has become a popular research field worldwide (Ojewumi, Fagbenro, 2019) [5]. However, the development of engineering education has entered a stage lacking innovative research and innovative practice. Kangas et al. (2017) believe that most engineering students have learning methods and the ability to pass exams, but lack in-depth and extensive learning capabilities [6]. Teachers hope to train them to adapt to economic and social changes and help them find a successful career path. In this process, they will inevitably ignore innovative education, which directly leads to the lack of students' innovative thinking, innovative ability, and independent learning (Murtagh, 2010; Crisp et al., 2019) [7]. Even some students have no idea about the definition of engineering or the knowledge required to obtain an engineering degree (Becker, 2010) [8]. The ability to innovate is precisely one of the key factors affecting the quality of talent training.

At the same time, compared with other countries, "examination-oriented education" is still a major issue in China's higher education. Although the reform of the teaching system has been carried out, colleges and universities cannot formulate corresponding professional exclusive comprehensive evaluation methods according to the actual situation: the focus of the current comprehensive evaluation standard is still on the test paper, the content of the evaluation is one-sided, and the evaluation method is single. At the same time, most of the problems are the mechanical application of teaching content, which is difficult to stimulate students' independence of thinking (Yang, Cheng, 2018) [9]. Practice is an important part of higher education. In teaching activities, practice usually takes two forms: active practice and passive practice. Active practice means that students choose the object, purpose, method, procedure, etc. of practice by themselves. The so-called passive practice means that the teacher gives the object, purpose, method, procedure and other elements of the practice. Students carry out practical activities within the framework set by the teacher and complete tasks in accordance with the established route. Passive practice is a form of practice that has existed for a long time in China's higher education, and it is also a common problem in China's higher education (Li, 2006) [10]. By comparing the differences in the evaluation of creativity between Chinese and other countries, it mainly depends on the following three factors: social values, school teaching practices and educational testing systems. Studies have shown that highly standardized tests may harm the development of students' creativity. Research results show that the innovation behaviour, current autonomy and cognitive needs of the previous freshmen are positively correlated with the individual innovation of college students (Martin et al., 2017) [11]. 
Innovation in the workplace is considered to be the key to the survival and success of an organization. As future workers, college students are the main source of future organizational innovation. Today's college students are the employees who will go to the society tomorrow, and college students are one of the important sources of future social environmental innovation. This is because college students are in the environment of higher education before entering the society. They begin to establish and develop their own outlook on life, world outlook, values and innovative behaviours as adults (Bowman, 2012) [12]. MJi (2013) believes that the cultivation of innovative talents must be carried out in students' daily learning activities and focus on the training of professional skills to promote students' personal growth and development [13]. In terms of personality education, Lin (2013) believes that cultivating students' innovative skills and emotional abilities is a due obligation of talent cultivation [14].

In response to the problems existing in the process of training innovative engineering talents, some colleges and universities have begun to actively explore the research and practice of engineering innovative talents training, such as school-enterprise cooperation. Traditional school-enterprise cooperation mainly includes two ways: talent exchange and co-construction of scientific research institutes and laboratories. Colleges and universities can hire senior engineers with front-line work experience as retired professors from companies, and senior engineers can actively participate in exchanges with students to gain practical experience in the company and broaden new ideas in the professional field. In addition, universities can use practical education as part of the cultivation of engineering students' innovative ability to form a continuous complementary relationship between universities and enterprises. For example, Durham University in the United Kingdom has increased the opportunities for students to cooperate with enterprises and society, and through practice has improved students' understanding of professional knowledge, which has increased the possibility of cultivating innovation capabilities (Winters et al., 2013) [15].

\section{CASE STUDY}

The software engineering undergraduate education program jointly organized by the School of International Education of Nanjing Institute of Technology and the University of Oulu in Finland adopts the " $4+0$ " training method. The four-year study of students is completed in China, and the undergraduate degree is awarded by China and Finland. The degree awarded by the University of Oulu can be recognized by the European Union system. The professional core courses of the students are taught face-to-face by professors from the University of Oulu in Finland. The young enterprise tutors participate in student training in all aspects and the whole process. In terms of the cultivation of students' innovation capability, the college has defined the goal of talent training, integrated its own advantages and resources, and built a student-centred The school-enterprise collaboration four-dimensional innovation capability training model, that is, the joint force of enterprise tutors and foreign teachers, student innovation capability training as the centre, professional courses and workshops as the basis, and college students' engineering innovation training projects as the carrier, all levels and types The innovation competition is a fostering model for college students' innovation capability.

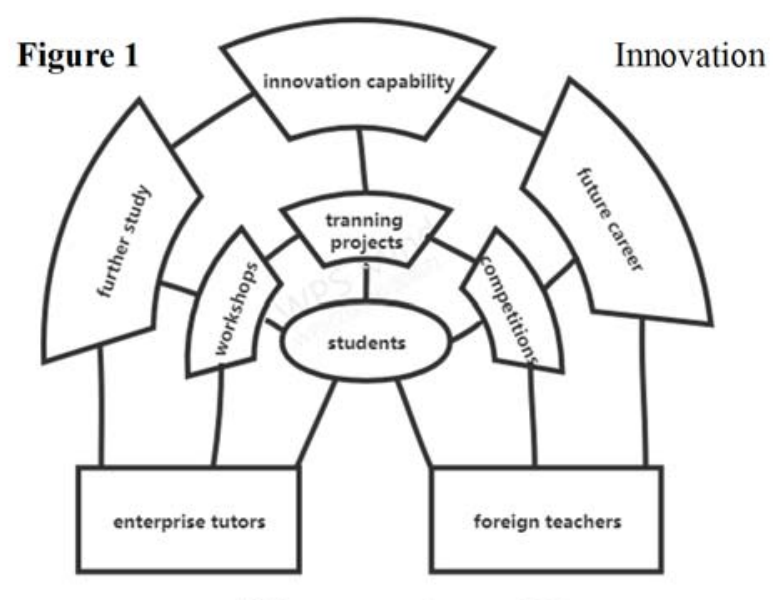

capability promotion modeI.

\subsection{A Joint Effort of Enterprise Tutors and Foreign Teachers.}

In the process of cultivating innovative talents, students are the main body, and the strength of teachers is the key and guarantee. The cultivation of students' innovative ability depends on the help and guidance of teachers (Betty Leask, 2004) believes that transnational education projects provide teachers with a unique opportunity to become cross-cultural learners [16]. It believes that these projects may improve their teaching in China, thereby improving the quality of "domestic and internationalization”. This is a basic principle that requires effort and commitment to internationalization, that is, the integration of cross-cultural aspects into higher education. However, the reconstruction of this role requires more communication between local tutors and transnational scholars, as well as "re-allocation of existing power relations" to establish a peaceful relationship between universities. But (Knight, 2015) cross-border scholars may provide a wide range of advantages, knowledge, and skills to teaching teams that are not easily accessible to local teachers [17]. The International Education College of Nanjing Institute of 
Technology focuses on establishing a team of teachers with strong sense of responsibility, high professional level and reasonable structure. The team includes both professors from the University of Oulu in Finland and tutor from local companies. In order to achieve the cultivation of students' innovative ability, the college attaches great importance to the grasp of the frontier of professional knowledge. The core professional courses are taught by professors from the University of Oulu in Finland. In terms of school-enterprise cooperation, young enterprise tutor are invited to participate in the whole process of talent training. , From the writing of the teaching plan of the workshop, the lectures, the summer practice links, to guiding students in the establishment, guidance, and problem solving of college students' engineering innovation projects, as well as guiding students to participate in engineering innovation competitions. Enterprise tutors participated in the cultivation of innovative talents. The whole process.

\subsection{Professional Courses and Workshops.}

No matter whether it focuses on the examination of basic knowledge and skills or the excavation of innovation capability, the engineering innovation training programs and subject competitions of college students have in common always in the basic theories, basic knowledge and basic skills of the subject, and these knowledge, theories and skills Mainly from classroom teaching. Therefore, in order to cultivate students' innovation capability through college students' scientific and engineering innovation training projects and subject competitions, we must grasp the important fulcrum of classroom teaching and further exert the basic role of curriculum teaching. The School of International Education of Nanjing Institute of Technology hired a professor at the academic frontier of the University of Oulu in Finland to teach students professional knowledge in the professional teaching of students, supplemented by Chinese teaching assistants to help academics overcome cultural barriers and answer students' various puzzles in time .

At the same time, in order to better train students majoring in software engineering in Sino-Finnish projects, expand students' extracurricular software engineering knowledge, and strengthen software engineering practice capabilities, the School of International Education of Nanjing Institute of Technology has set up a summer practice link in the training program, with the purpose of further strengthening Curriculum construction, innovative talent training models, and the use of summer vacation to give students more choices. The workshops of the School of International Education of Nanjing Institute of Technology are divided into two categories: theoretical and practical. Theoretical workshops are a useful supplement for innovative thinking, scientific research methods, and international literacy. The practical links are in the form of group classes and A practical process of introducing enterprise engineers for course design and professional training.

\subsection{Engineering Innovation Training Projects}

Innovative capability includes innovation consciousness, innovative thinking and innovative skills. The core of innovative ability is innovative thinking. The improvement of college students' innovative ability is the result of the simultaneous development of knowledge, skills and strategies. The innovation capability training model based on the scientific and engineering innovation training project, that is, the scientific and engineering innovation training project for college students, is a practical process of in-depth understanding of knowledge, systematic organization and creative exertion. In view of the fact that the cultivation of innovation capability is a long-term and systematic work, and the general classroom teaching lacks pertinence here, it is necessary to introduce college students' engineering innovation training projects with "innovative spirit” as the core value as the carrier of innovation capability, through combing the engineering of college students The categories and characteristics of innovative training programs are combined with professional practice, and a corresponding training system is established on this basis to systematically cultivate students' innovative ability. The essence of the college student engineering innovation training program is to cultivate students' innovative spirit and ability. However, how to do this effectively requires the support of corresponding training programs. Because of its high degree of comprehensiveness and flexibility, the college students' engineering innovation training program requires students to continuously improve their innovation consciousness and innovative thinking on the basis of consolidating basic knowledge and skills. Training for "innovation" is undoubtedly an engineering innovation training program Core. The college student engineering innovation training program requires students to independently write a series of creative work such as project application writing, pattern design, sample production, report writing, thesis publication, patent application, and report defence, and finally present the outstanding entries, which forms A continuous and rigorous training program for innovation capability was established.

Currently, among the 283 students majoring in software engineering in SIE of Nanjing Institute of Technology , A total of 148 people participated different kinds of funding of university students' engineering innovation projects. 15 papers published as the first author, including 3 papers indexed by EI and SCI. 


\subsection{Engineering Innovation Competitions}

Taking innovation competition as the driving force for the cultivation of talent innovation capability, which means taking the competition project as the environment and the content of the competition as the problem object, requiring students to comprehensively use the knowledge they have learned, formulate reasonable technical training programs, and guide students to solve problems creatively, so as to cultivate students The purpose of innovation. It contains two meanings: one is to train students' innovative consciousness and innovative thinking through college students' engineering innovation competition; the other is to train students' innovative skills through college students' engineering innovation competition, that is, to make students proficient in the process of college students' engineering innovation competition. Master various basic skills and generate innovative skills under the guidance of innovative thinking. Therefore, in subject competitions, strengthening technical training is the key to cultivating innovation capability, and it is also the most effective means. The engineering innovation competition for college students is an important way to cultivate students' innovation capability. The Sino-Finnish project introduces enterprise engineers to participate in the cultivation of students' innovation capability and participate in competitions, assist students in completing innovative projects and competitions, and strive to produce high-quality project results. Finnish professional course teachers and Chinese local enterprise instructors work together, professional courses and workshops as the basis, university students' engineering innovation training projects as the carrier, and various innovation competitions at all levels as the thrust. The four are in different stages of the time axis for university students' innovative ability Cultivation provides interactive support, which is relatively independent and closely related. They interact, interlock and promote each other, thus forming a relatively complete and three-dimensional closed-loop innovation capability training system.At present, more than 70 of SIE have participate $\mathrm{d}$ in innovation competition projects, who have won 26 school level and above innovation competition awards, including 5 national-level awards, and 12 provinciallevel awards.

\section{CONCLUSION}

A good training model for innovative talents must be a complete engineering system. Therefore, it must proceed from a systematic perspective and consider all factors influencing the cultivation of innovation capability, including basic knowledge and theories, basic skills and training methods, etc.

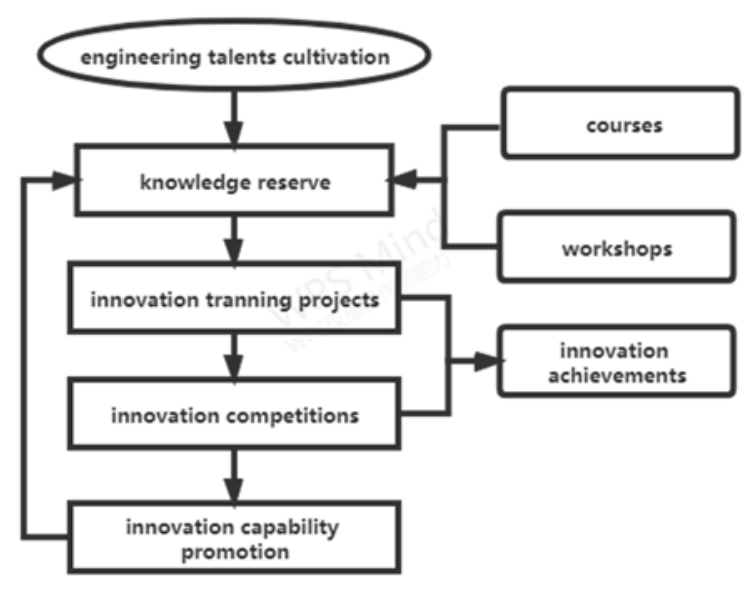

Figure 2 Concept of innovation talents cultivation.

\subsection{Systematic}

The process of college students' scientific and engineering innovation activities is a process that requires students to deeply and systematically understand relevant knowledge and flexibly combine theory with practice. It is also a typical practical process. The goal of the innovation capability training model for college students is to cultivate the innovation capability of college students, and every link in the training model must be based on this principle and focus on cultivating innovation capability.

\subsection{Feasibility}

The training model must have strong applicability and manoeuvrability, have goals, content, organization, measures, and monitoring, can be put into practice, and can really play a role in cultivating students' innovative ability in the process of practice. At the same time, as a talent training model, it must and can accept assessment and evaluation. That is, each teaching link in the model should have corresponding teaching quality standards or norms to facilitate the assessment and evaluation of the teaching effect of the model to ensure the Feasibility and practicability of the model.

\subsection{Guarantee Mechanism}

Guarantee mechanism is an important means to ensure the stable and efficient operation of the training model. The establishment of a training model for innovative engineering talents must be continuously improved from three aspects.

\subsubsection{Standardization of Management}

Formulate corresponding teaching management rules and regulations, improve related quality standards and technical specifications, and ensure that all tasks are carried out in an orderly and standardized manner. 
Strictly supervise and supervise relevant enterprise instructors in accordance with teaching and guidance plans, quality standards, guidance objectives and other documents; continuously coordinate, supervise, and improve relevant management systems and norms to ensure that teaching management can be based on.

\subsubsection{Quality Control and Feedback}

The innovative ability training model involves many aspects such as theoretical teaching, training practice, and organization management. There are many links, long cycles, and complex processes. Each link may affect the teaching effect. In addition, the competition characteristics of various disciplines are different, making the model under this model The quality of teaching is difficult to control. Therefore, in the near future, we will gradually establish a corresponding quality monitoring and feedback mechanism to monitor each link of teaching, training, and guidance. In short, in the teaching process, it is necessary to timely and effectively monitor the actual teaching quality and quality compliance of each link, discover problems in time, and correct errors to ensure the quality and efficiency of various teaching and training.

\subsubsection{Constraints and Incentives}

Subject competition is an arduous job. It not only requires participating students and instructors to spend more time and energy, but also bears the risk of losing the competition. Establishing a system of rewards and punishments based on the principle of combining responsibilities, powers, and benefits with a comprehensive assessment basis will be more conducive to encouraging teachers and students to actively participate in this work. As far as students are concerned, in addition to material rewards, students with outstanding performance can be appropriately rewarded. In addition to material rewards, credits reduction, exemption from examinations for admission to graduate students, and priority recommendation for employment can also be considered; for teachers, the competition scores can be compared with the teacher's bonus and professional title evaluation. Recruitment, annual appraisal, evaluation and prioritization are linked. In this way, it not only fully affirms the labor achievements of teachers and students, but also provides a guarantee for the sound development of discipline competition work, thereby promoting the realization of the goal of cultivating students' innovative ability through discipline competition. However, while advancing in this way, we must pay attention to avoiding the only grade theory. After all, this is a teaching process for cultivating talents, and the process is more important than the result.

\subsection{Corresponding Education Reform Measures}

For college students' engineering innovation training projects and innovation discipline competitions, corresponding series of teaching reforms are bound to require corresponding series of teaching reforms. Therefore, it is very important to establish a curriculum teaching and management system that aims at cultivating students' innovative ability and bases on college students' engineering innovation training projects. Such as reforming the curriculum and teaching system, strengthening the construction of the teaching staff, and creating a campus innovation culture. Therefore, the significance of the college student engineering innovation training project as an important carrier to promote the cultivation of innovative talents is beyond doubt.

This article takes the training of engineering innovative talents by the International Education College of Nanjing Institute of Technology as an example, discusses the constituent elements, participants and implementation paths of the engineering innovative talent training model. From the perspective of the main body of the engineering innovative talent training model, re-examine the main elements of education. Colleges, enterprises, foreign professional course teachers, and Chinese local enterprise tutors should be included in the innovative talent training system, and the cultivation of student innovation capability should be integrated into innovative projects. The whole process of talent training is in order to meet the requirements for innovative engineering talents in the context of globalization.

\section{AUTHORS’ CONTRIBUTIONS}

Yu Liu, Boshuai Ye, Jing Liu, Chao Dong designed research, performed research, and wrote the paper.

\section{ACKNOWLEDGMENTS}

This research was financially supported by two projects including the Humanity and Social Sciences Research Project of Nanjing Institute of Technology (N o: SKLA202022), the Philosophy and Social Sciences Research Project in Universities of Jiangsu Province (No: 2020SJB0153).

\section{REFERENCES}

[1] Wu, Y. Hou, Q. Yang, J. Hao, accelerating develop ment and construction of emerging engineering; ta king initiative to adapt to and lead the new econom y, Research in Higher Education of Engineering 1( 1) (2017) 1-9. DOI: https://CNKI:SUN:GDGJ.0.20 17-01-002 
[2] D. Zhong, Connotations and actions for establishing the emerging engineering education, Research in Higher Education of Engineering 1(3) (2017) 1-6.

[3] J. Xi, (2018), To persist in the development of soci alist education with Chinese characteristics and to c ultivate students into socialist builders and success ors who develop comprehensively in virtue, intellig ence, physical, aesthetic and diligence, available at, https://www.moe.gov.cn/jyb_xwfb/s6052/moe_83 8/201809/t20180910_348145.html, referred on 14/ 05/2020.

[4] S. Al-Husseini, E. Ibrahim, Transformational leadership and innovation: A comparison study between Iraq's public and private higher education. Studies in Higher Education 41(1) (2016) 159-181. https://DOI: 10.1080/03075079.2014.927848

[5] K.A. Ojewumi, D.A. Fagbenro, Entrepreneurial intention among polytechnic students in Nigeria: the role of self- efficacy and social networks, International Journal of Entrepreneurial Knowledge 7(1) (2019) 20-30. DOI: https://10.2478/ijek-20190002

[6] J. Kangas, E. Rantanen, L. Kettunen, How to facilit ate freshmen learning and support their transition $\mathrm{t}$ o a university study environment, European Journa 1 of Engineering Education 42(6) (2017) 668-683. DOI: https://org/10.1080/03043797.2016.1214818

[7] L. Murtagh, They give us homework! Transition to higher education: the case of initial teacher trainin g, Journal of Further and Higher Education 34(1) ( 2010) 405-418. DOI: https://org/10.1080/0309877 x.2010.484057

[8] F. Becker, Why don't young people want to becom e engineers? Rational reasons for disappointing dec isions, European Journal of Engineering Education
35(4) (2010) 349-366. DOI: https:// org/10.1080/03 043797.2010 .489941

[9] P. Martin, K. Potocnik, A. Fras, Determinants of st udents' innovation in Higher Education, Studies in Higher Education 42(7) (2017) 1229-1243. DOI:htt ps://doi.org/10.1080/03075079.2015.1087993

[10] N.A. Bowman, Promoting sustained engagement w ith diversity: The reciprocal relationships between $\mathrm{i}$ nformal and formal college diversity experiences, $\mathrm{T}$ he Review of Higher Education 36(1) (2012) 1-24. DOI: https://10.1353/RHE.2012.0057

[11] B. Ji, (2013), The criteria to identify international t alents lie in innovation rather than overseas educati on background, available at, https://www.chinanew s.com/edu/2012/0612/3956751.shtml, referred on 1 2/06/2012.

[12] J. Lin, (2013), Special protections are needed for sp ecial overseas education-reflections on improving q uality of Sino-Foreign cooperative education, avail able at, https://edu.people.com.cn/n/2013/0315/c1 053-20807312.html, referred on 15/03/2013.

[13] K. Winters, H. Matusovich, M. Brunhaver, H. Che $\mathrm{n}$, From freshman engineering students to practicin g professionals: changes in beliefs about important skills over time, in: 120th ASSE annual conference \& exposition, 23-26 June 2013, pp.1-20, DOI: http s://org/10.18260/1-2-19635

[14] B. Leask, Transnational Education and Intercultura l Learning: Reconstructing the Offshore Teaching Team to Enhance Internationalisation, in: Proceedi ngs of the Australian Universities Quality Forum, 2 004, DOI: https://10.1.1.114.9090

[15] J. Knight, Updating the definition of internationaliz ation, International Higher Education 33(1) (2003) . DOI: https://doi.org/10.6017/ihe.2003.33.7391 